\title{
Statistical analysis of the driving forces of anthropogenic impact on the environment
}

\author{
Mikhail G. Prokopyev*, and Anton D. Vitukhin \\ Federal State Budgetary Scientific Institution "Institute of Market Problems of the Russian Academy \\ of Sciences", Nakhimovsky prospect, 47, 117418Moscow, Russia
}

\begin{abstract}
The aim of the study is to analyze the driving forces of the impact of human activities on the environment. The problem of assessing the influence of the population size, the level of economic development, as well as the technological factor on the volume of emissions of pollutants into the atmospheric air in the regions of the Russian Federation is considered. A retrospective of models for analyzing the main driving forces of anthropogenic impact on the environment is presented. The study is based on the STIRPAT model. The results of the econometric assessment showed that both the population and the level of economic development (GRP per capita) have a decisive influence on the increase in air emissions in the regions of the Russian Federation. A decrease in the energy intensity of GRP, as well as the share of manufacturing and extractive industries in the sectoral structure of GRP, also leads to a significant decrease in the environmental load. However, the values of the corresponding environmental elasticities are significantly lower than the elasticities of emissions of pollutants into the atmosphere with changes in population size and economic growth (GRP per capita).
\end{abstract}

\section{Introduction}

Human economic activity is the main cause of the environmental pollution [1], [2]. The problem of identifying and analyzing the driving forces of anthropogenic impact on the environment was posed in the 70 s of the last century and received the most concentrated expression during the discussion between B. Commoner on the one hand, P. Ehrlich and J. Holden on the other. What is the cause and what are the consequences of the anthropogenic impact? B. Commoner believed that the deterioration of the environment in the United States after World War II was caused primarily by changes in the production technologies. In turn, P. Ehrlich and J. Holden, in particular, argued: "when establishing the blame for the environmental degradation only on defective technologies, B. Commoner's position is uncomplicated, socially convenient and, therefore, seductive. But there is no point in misleading the public on these issues; the truth is that we must fight concurrently with overpopulation, over abundance and defective technology" [5]. P. Ehrlich and J. Holden believed that all three factors affecting the environment were important, but at the same

\footnotetext{
* Corresponding author: mgprokopyev@yandex.ru
} 
time emphasized the role of population growth. Population growth, economic growth, resource use and environmental degradation must be considered in conjunction.

The article includes a historical retrospective of models for analyzing the main driving forces of anthropogenic impact on the environment, research methodology, main results and discussion, and a conclusion. The information background of the study is the data of Rosstat for the regions of the Russian Federation for 2018.

\section{Historical retrospective}

One of the most famous and widely used model for analyzing the main driving forces of anthropogenic impact on the environment is the IPAT. This model was first proposed in the early 1970s [4], [5]. The model classifies factors affecting the state of the environment into three driving forces: population size, wealth (welfare), represented by consumption or production per capita, and the level of technology used. The formulation of the relationship between environmental impact and driving forces of environmental impact in this model is represented by a simple specification:

$$
\mathrm{I}=\mathrm{P} \cdot \mathrm{A} \cdot \mathrm{T} \text { or } \mathrm{I}=\mathrm{PAT},
$$

Where $\mathrm{I}$ is the overall impact on the environment, A is wealth (welfare), $\mathrm{P}$ is the population size, and $\mathrm{T}$ is the technological level. In most empirical applications, the IPAT is an identity because the factor $\mathrm{T}$ is calculated as the environmental impact per unit of wealth:

$$
\text { Impact }=\text { population } \cdot \frac{\text { wealth }}{\text { population }} \cdot \frac{\text { impact }}{\text { wealth }} .
$$

The $\mathrm{T}$ factor is often adapted to a problem addressed by the IPAT. For example, in the case when the impact of human activity on climate change is assessed, an indirect indicator of the technological level $\mathrm{T}$ is greenhouse gas emissions per unit of wealth:

$$
\text { Emissions }=\text { population } \cdot \frac{\text { wealth }}{\text { population }} \cdot \frac{\text { emissions }}{\text { wealth }} \text {. }
$$

The IPAT specification assumes that each factor has a proportionate impact on the environment. The growth of one of the factors, for example, A, twofold leads to a doubling of its negative impact on the environment, while other variables remain unchanged. On the other hand, this does not mean that other factors do not affect the level of exposure. Even remaining unchanged, the other factors "scale" the consequences of a change in A in the impact on the environment (a change in one factor is multiplied by the level of other factors). Note that (1) is a multiplicative equation. The multiplier effect leads to the fact that a relatively small, simultaneous percentage increase in each of the three factors leads to a sharp increase in the overall impact. In [5] a simple arithmetic example is given that illustrates the above.

A fundamental issue in assessing the significance of various driving forces of anthropogenic impact on the environment within the IPAT framework is the presence or absence of interdependence of variables on the right side of the identity. The assumption of independence between the variables on the right side of the IPAT is a necessary condition for the applicability of the decomposition method underlying this specification [6]. In reality, this assumption is not obvious and is not fulfilled in all cases. In particular, it is difficult to expect that changes in per capita wealth are independent of population growth and that there is no relationship between per capita income and emissions per gross domestic product. The IPAT specification also assumes that there are no other factors other 
than population, wealth and the level of technology used that determine the negative impact on the environment. In other words, the factor $\mathrm{T}$ includes other factors as well.

P. Waggoner and J. Ausubel used IPAT as a basis for clarifying and justifying leverage to reduce the environmental harm or factors that can be changed to reduce the impact of driving forces on the environment [10]. Applying a decomposition method, they disaggregated $\mathrm{T}$ (emissions $\mathrm{CO}_{2}$ per unit of GDP) into energy consumption per unit of GDP (C) and emissions $\mathrm{CO}_{2}$ per unit of energy consumption (T). This modification of the IPAT model was named ImPACT:

$$
\mathrm{I}=\mathrm{PACT}
$$

The traditional IPAT specification, when analyzing the impact of anthropogenic driving forces on carbon dioxide emissions $\mathrm{CO}_{2}$, assumes that emissions (I) are derived from population (P), GDP per capita (A), and emissions $\mathrm{CO}_{2}$ per unit of GDP (T). In contrast, ImPACT shows that emissions $\mathrm{CO}_{2}(\mathrm{I})$ are due to population $(\mathrm{P})$, GDP per capita (A), energy consumption per unit of GDP $\left(\mathrm{C}\right.$ ), and specific emissions $\mathrm{T}$ (emissions $\mathrm{CO}_{2}$ per unit of energy consumption).

The main advantage of IPAT (ImPACT) is that it is a "lean" specification that explains the relationship between driving forces and their impact on the environment. At the same time, the hypotheses about the relationship between anthropogenic factors and their impact on the environment should not only be specified by the structure of the model, but be supported by empirical data. To assess and test the corresponding hypotheses T. Dietz and Eu. Rosa reformulated the IPAT [3]. The new model was named as STIRPAT ("Stochastic Impacts by Regression on Population, Affluence and Technology"). The basic version of STIRPAT is represented by the regression equation (5):

$$
I_{i}=\delta P_{i}^{\alpha} A_{i}^{\beta} T_{i}^{\gamma} \mu_{i}
$$

where $\mathrm{P}$ - population size, A - prosperity, T - technological level, $\mu_{i}$ - statistical error, $i$ country (region) index. Note that $\alpha, \beta$, and $\gamma$ can be either the parameters or more complex functions that are estimated using the standard statistical procedures.

This regression model can be empirically tested using the econometric methods. Due to the complexity of interpretation and the lack of appropriate quantitative indicators for assessing the technological level variable, T. Dietz and Eu. Rosa use a simplified version of the model[3]. This model specification does not include a variable that characterizes the technology level. Its influence is assumed to be reflected in the statistical error (the remainder includes all factors that are not population or wealth). Therefore, the following specification of the STIRPAT model is tested:

$$
I_{i}=\delta P_{i}^{\alpha} A_{i}^{\beta} \mu_{i},
$$

At the same time, a number of indicators can be used as technological level proxies. Such indicators N. Grunewald and I. Martinez-Zarzoso include the indicator of industrial activity, measured by the share of manufacturing in the sectoral structure of GDP, as well as energy efficiency of GDP, which is calculated as the volume of GDP per unit of primary energy consumption [7].

\section{Research methodology}

The study is based on the STIRPAT model. The parameters in the logarithmic specification of equation (5) represent the elasticities of the driving forces, or the percentage change in environmental impact when a particular driving force changes by one percent (with the 
remaining driving forces unchanged). These parameters, by analogy with the elasticities of supply and demand, are called the "environmental elasticities" [9]. Environmental elasticity $E E$ is interpreted as the marginal environmental impact of the respective driving forces. In particular, taking into account the STIRPAT specification: $E E_{I P}$ - elasticity of the impact on the environment with a change in the population size, $E E_{I A}$ - elasticity of the impact on the environment with a change in wealth and $E E_{I T}$ - elasticity of the impact on the environment with a change in the technological level. $E E_{I P^{-}}$characterizes the change in the impact on the environment when the population changes by $1 \%$ (with a constant level of other driving forces). Accordingly, $E E_{I A}$ - change in the impact on the environment with a change in the level of wealth by $1 \%$ (with a constant level of other driving forces). The elasticity of the impact of the technological level $E E_{I T}$ is determined depending on the proxy indicator underlying it, for example, the energy intensity of the GRP. In this case, $E E_{I T}$ - change in the impact on the environment with a change in energy intensity by $1 \%$ (with a constant level of other driving forces).

To substantiate the role of the population in the impact on the environment, to assess the responsibility of economic growth for the deterioration of its state in the regions of the Russian Federation, the following variables were adopted: population size and GRP per capita (a measure of wealth). Indirect indicators of the technological level are the industrial activity, which is calculated as the share of manufacturing and extractive industries in the sectoral structure of GRP, and the energy intensity of GRP, measured as the ratio of primary energy consumption to the volume of GRP. The negative impact on the environment is considered through air pollution (the level of pollutant emissions). The following specifications of equation (5) are given below:

Regression - emission depending on population size and GRP per capita:

$$
\ln I_{i}=\ln \delta+\alpha \ln P_{i}+\beta \ln A_{i}+\ln \mu_{i} .
$$

Regression - emissions from population size, GRP per capita and GRP energy intensity:

$$
\ln I_{i}=\ln \delta+\alpha \ln P_{i}+\beta \ln A_{i}+\delta \ln E_{i}+\ln \mu_{i} .
$$

Regression - emissions from the population, GRP per capita and the share of manufacturing and extractive industries in the sectoral structure of GRP:

$$
\ln I_{i}=\ln \delta+\alpha \ln P_{i}+\beta \ln A_{i}+\tau \ln S_{i}+\ln \mu_{i}
$$

Regression - emissions from population, GRP per capita, shares of manufacturing and extractive industries in the sectoral structure of GRP and energy intensity of GRP:

$$
\ln I_{i}=\ln \delta+\alpha \ln P_{i}+\beta \ln A_{i}+\tau \ln S_{i}+\delta \ln E_{i}+\ln \mu_{i},
$$

Where $E_{i}$ is the GRP energy intensity; $S_{i}$ - share of manufacturing and extractive industries in the sectoral structure of GRP ; $\alpha, \beta, \delta, \tau$ - parameters of regression equations; $\ln \delta$ - constant of the equation; $\ln \mu_{i}$ - statistical error. The logarithmic specification of the equations (7) - (10) allows one to interpret $\alpha, \beta, \delta, \tau$ as corresponding to the elasticities. In particular, $\alpha$ is the elasticity of the emissions with a change in the population size, $\beta$ is the elasticity of emissions with a change in GRP per capita, $\delta$ is the elasticity of emissions with a change in the energy intensity of GDP, and $\tau$ is the elasticity of the emissions with a change in the share of manufacturing and extractive industries in the sectoral structure of GRP.

Three main hypotheses are considered:

H1: There is a positive relationship between the emissions and population, as well as GRP per capita. 
H2: GRP energy intensity has a significant impact on the level of the emissions into the air.

H3: The growing share of manufacturing and extractive industries in the sectoral structure of GRP has a negative impact on the state of atmospheric air.

\section{Main results and discussion}

The main results of the econometric estimation of the regression equations (7-10) are shown in Table 1.

Table 1. Econometric estimation of regression equations

\begin{tabular}{|c|c|c|c|c|c|c|c|}
\hline 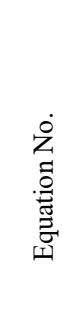 & 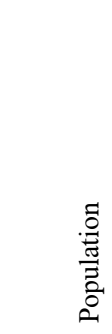 & 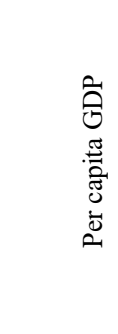 & 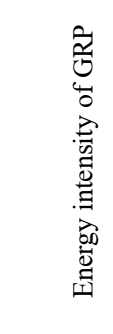 & 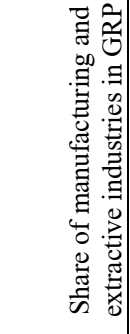 & $R^{2}$ & $F$ & 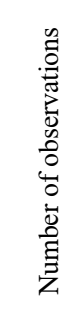 \\
\hline & $\alpha$ & $\beta$ & $\delta$ & $\tau$ & & & \\
\hline 7 & $\begin{array}{c}0.892^{* * *} \\
(17.35)\end{array}$ & $\begin{array}{l}0.704^{* * *} \\
(9.58)\end{array}$ & & & 0.837 & 209.931 & 85 \\
\hline 8 & $\begin{array}{c}0.882^{* * *} \\
(18.56) \\
\end{array}$ & $\begin{array}{c}0.831^{* * *} \\
(10.75) \\
\end{array}$ & $\begin{array}{c}0.288^{* * *} \\
(3.59) \\
\end{array}$ & & 0.859 & 164.461 & 85 \\
\hline 9 & $\begin{array}{c}0.879^{* * *} \\
(18.23)\end{array}$ & $\begin{array}{l}0.522^{* * *} \\
(6.09) \\
\end{array}$ & & $\begin{array}{c}0.307^{* *} \\
(3.57)\end{array}$ & 0.859 & 164.250 & 85 \\
\hline 10 & $\begin{array}{l}0.882^{* * *} \\
(18.85)\end{array}$ & $\begin{array}{l}0.665^{* * *} \\
(6.55)\end{array}$ & $\begin{array}{c}0.208^{* *} \\
(2.45)\end{array}$ & $\begin{array}{c}0.220^{* *} \\
(2.43)\end{array}$ & 0.869 & 132.308 & 85 \\
\hline
\end{tabular}

Calculated values of $t$ - statistics, $* * *$ - significance level $0.01, * *$ - significance level 0.05 are given in brackets.

Analysis of the Table 1 shows that both population size and per capita GRP (an indicator of economic growth) have a positive and statistically significant effect on the emissions. From equation (7) it follows that the elasticity of the impact on the environment with a change in the population size by $1 \%$ at a constant level of per capita GRP is 0.89 . In turn, the elasticity of the impact on the environment when the GRP level changes by $1 \%$ with a constant population size is 0.7 . Both are true at a significance level of 0.01 . At the same time, the identified relationship explains almost 84 percent of interregional differences in the emissions. $\left(R^{2}=0.84\right)$. The remaining 16 percent of the change in the emissions is due to the factors not accounted for in the specification (7) of the model under consideration.

Variables that indirectly characterize the level of technologies used, the energy intensity of the GRP, as well as the share of manufacturing and extractive industries in the GRP, have a negative impact on the state of the atmospheric air (the corresponding elasticities take positive values). The elasticity of the environmental impact of the GRP energy intensity is 0.28 (statistically significant at the level of 0.01 ) - specification (8). The elasticity of the environmental impact of the share of manufacturing and extractive industries in GRP is 0.3 (statistically significant at the level of 0.01) - specification (9). Specification (10) includes the cumulative effect of all considered factors. A decrease in the energy intensity of GRP, as well as the share of manufacturing and extractive industries in GRP, both in (8) and (9), and in (10) have a positive effect on the state of the environment. 
However, the values of the corresponding elasticities are significantly lower than the elasticities of emissions of pollutants into the atmosphere with changes in population size and economic growth (GRP per capita).

\section{Conclusion}

The data presented is consistent with previous results for other countries. The results of the studies using the STIRPAT model in the context of various provinces of China have shown that the greatest anthropogenic impact is exerted by the growth of the population and the level of wealth (GRP per capita) [8]. Involvement of other factors has a statistically significant effect on the level of emissions. However, they have an insignificant effect on the level of impact on the environment and do not significantly affect the elasticity of the impact on the environment of the population and the level of wealth (GRP per capita). It does not follow from the results obtained that in order to solve the environmental problems, it is necessary to implement the scenarios of zero growth in both the population and the level of economic development. The aim of Russia's modern development strategy is to reduce the adverse impact on the environment in a growing economy. The use of more efficient, best available technologies helps to overcome the consequences of economic growth contributing to environmental degradation. In recent years, a number of countries with high levels of GDP per capita have largely eliminated the relationship between pollution and economic growth and are showing a decrease in emission intensity (decoupling effect).

\section{Acknowledgements}

The topic within the framework of the state assignment for the implementation of fundamental scientific research 0163-2019-003 "Problems of sustainable development of Russia: ecological and economic aspect".

\section{References}

1. M.G. Prokopyev, A.D. Vitukhin, Regional problems of economic transformation,8 (106), 175 (2019)

2. A.S. Tulupov, A.F. Mudretsov, M.G. Prokopyev, Ecology and Industry of Russia,23(6), 41 (2019)

3. T. Dietz, Eu. Rosa, PNAS,94(1), 175 (1997)

4. P. Ehrlich, J. Holden, Science, 171, 1212 (1971)

5. P. Ehrlich, J. Holden, The Bulletin of the Atomic Scientists,28(5), 16 (1972)

6. O. Gans, F. Jöst, Discussion Paper Series, 422 (2005)

7. N. Grunewald, I. Martínez-Zarzoso, Discussion Papers from Ibero-America Institute for Economic Research,212(2011)

8. J. Jia, H. Deng, J. Duan, J. Zhao, Ecological Economics,68, 2818 (2009)

9. R. York, Eu. Rosa, T. Dietz, Ecological Economics,46, 351(2003)

10. P.E. Waggoner, J.H. Ausubel, PNAS,99(12), 7860 (2002) 